\title{
Impact of chronic venous disease on quality of life: Results of vein alarm study
}

\author{
DACIANA-ELENA BRANISTEANU ${ }^{1}$, TONI FEODOR ${ }^{2}$, SORIN BAILA $^{3}$, \\ IULIANA-ALMA MITEA ${ }^{4}$ and OANA VITTOS ${ }^{5}$
}

\author{
${ }^{1}$ Department of Dermatology, University of Medicine and Pharmacy 'Gr. T. Popa', 700115 Iasi; ${ }^{2}$ Medical Center for \\ Diagnosis, Ambulatory Treatment and Medical Prevention, Surgery Clinic 'Sf. Nicolae', 011796 Bucharest; \\ ${ }^{3}$ Department of Vascular Surgery, 'C.C. Iliescu' Emergency Institute for Cardiovascular Diseases, \\ 022322 Bucharest; ${ }^{4}$ Servier Pharma, 013714 Bucharest; ${ }^{5}$ Medone Research, 050475 Bucharest, Romania
}

Received July 03, 2018; Accepted August 21, 2018

DOI: $10.3892 /$ etm.2018.7054

\begin{abstract}
Chronic venous disease (CVD) affects millions of people and negatively impacting the patient's quality of life (QoL) and most of the patients are diagnosed with CVD in advanced stages. The impact of newly diagnosed CVD on QoL has not been evaluated by other studies in Romania. The aim of this study was to assess the QoL for adult patients newly diagnosed with CVD addressing to the General Practitioner's (GP) office in Romania between June to August 2016. Patients included in the study were adult, signing the inform consent form, newly diagnosed with CVD or patients diagnosed with CVD, without CVD treatment the past 6 months. Data on demographic distribution, risk factors, clinical profiles, CVD symptomatology, QoL parameters, as well as pharmacological management practice were collected. The study included 1,893 patients $(79.08 \%$ females) with $50.4 \%$ of patients in the age group 51-70 years. The most frequent CVD symptoms reported, were heavy leg sensation $(85.74 \%)$, swelling of the feet $(77.28 \%)$ and pain $(73.11 \%)$. The most frequent CVD signs were telangiectasia and reticular veins $(79.19 \%)$, varicose veins $(65.77 \%)$ and edema $(53.35 \%)$. The clinical, aetiological, anatomical and pathophysiological (CEAP) classification placed most of the patients in C3 class (31.85\%), followed by C2 class $(28.00 \%), \mathrm{C} 1$ class $(21.02 \%)$ and $\mathrm{C} 4 \mathrm{a}(8.87 \%)$. Most of the patients reported 'low' or 'moderate' intensity of the CVD symptoms. QoL was affected for most of the patients at 'a mild' or 'moderate' degree, being noticed as a significant negative impact on physical, psychological, and social functioning components of QoL, correlated with CEAP class $(\mathrm{P}<0.001)$. Data regarding correlation of CEAP
\end{abstract}

Correspondence to: Dr Oana Vittos, Medone Research, 11th Grigore Taranu Street, 5th Sector, 050475 Bucharest, Romania E-mail: toanaoana@medone.ro

Key words: chronic venous disease, epidemiology, symptomatology, CEAP, quality of life class, CVD symptoms and impact on QoL identified a significant correlation between all analyzed components $(\mathrm{P}<0.001)$. Study results prove that CVD diagnosis was established with relative delay and CVD is negatively affecting patients' QoL. Additional research will be needed to identify the long-term impact of CVD on QoL of the affected patients and their families.

\section{Introduction}

Chronic venous disease (CVD) affects millions of people and most of the patients are diagnosed with CVD in advanced stages (1-5). The estimated prevalence of varicose veins varies between 5 and $30 \%$ in the adult population and with a female to male predominance, respectively 3 to 1 . Other data are suggesting a higher male prevalence (3). According to most authors, risk factors include age, sex, a family history of varicose veins, obesity, pregnancy, phlebitis, previous leg injury and behavioural factors such as prolonged standing and perhaps a sitting posture at work $(6,7)$. At the initiative of the Union Internationale de Phlébologie, a large-scale international survey named Vein Consult Program (VCP) was carried out in 20 countries. The VCP concluded that the worldwide presence of CVD was $83.6 \%$ and the study underlined the importance of adequate screening for CVD and training of both GPs and specialist physicians (1). The main goal of CVD treatment is reducing the symptoms (heaviness, leg pains, oedema and swelling) and improving the patient's quality of life (QoL), which is affected in many patients. QoL can be defined as the functional effect of the disease, respectively of the treatment of the disease, as perceived by the patient (8) and there are specific validated scales which are able to collect data regarding different QoL parameters.

It is well-known that CVD negatively impacts the well-being of the patients, both at the physical and the psychological levels, nevertheless there is still a paucity of scientific data regarding the impact of CVD on QoL, and according to our knowledge, there is no other epidemiological research performed in Romania to evaluate the impact of newly diagnosed CVD on all CIVIQ-20 items regarding quality of life. 


\section{Materials and methods}

The study was multicentre, prospective and observational and took place in Romania, based on a transversal method. In this study adult patients were recruited by 110 investigators, located in Romania's urban area. The recruitment took place in June to August 2016 and included 1,893 patients. The investigators were general practitioners (GPs) selected in compliance with national regulations, in a randomly manner, and the purpose of this study was to collect information about CVD presence, demographic data, frequency of disease's signs and symptoms, associated risk factors, therapeutic management practice and impact on QoL parameters of patients with diagnosed with CVD.

The investigators' responsibility was to establish and maintain a treatment compliant with current medical practice guidelines and in the best interest of the patient. In this study, no medical analyses or specific treatments were prescribed, thus the patients' care was not influenced by the participation in this study.

Each investigator included 18 consecutive patients who attended the practice for various reasons. Patients selection was based on the following criteria: Patients with the minimum age at inclusion 18 years, newly diagnosed with CVD or patients diagnosed with CVD, but without treatment for CVD within the last past 6 months, or prior inclusion. Patients attending for emergency visits were excluded. Informed consent was obtained from each participant.

The study visit consists in an initial GP interview regarding age, sex, height, weight, BMI, occupation, reason for addressing GP, level of daily physical activity, hours spent standing and sitting. For women additional data regarding number of births, as well as the use of hormonal replacement therapy and/or birth control pills was recorded.

Data regarding presence of CVD symptoms were recorded and their magnitude was self-evaluated by each of the patients on a VAS scale (heavy legs, pain in the legs, sensation of swelling or burning, night cramps). The time when symptoms occurred at highest intensity, as well as the other possible CDV signs noticed during clinical examination (oedema, spider veins, varicose veins, skin modifications, or ankle ulcers) were recorded. For each patient the GPs evaluated the clinical, aetiological, anatomical and pathophysiological (CEAP) clinical stages by visual examination. In addition, CVD therapeutic management recommendations and duration of prescribed treatment was recorded.

Each patient completed the CIVIQ-20 questionnaire regarding QoL. CIVIQ-20 is a reliable, validated instrument valuable in assessing the treatmenteffects in longitudinal, multinational studies of patients with chronic venous disease (9).

Based on the results of the CIVIQ 20 questionnaire the Global Index Score (GIS) was calculated as the difference between the final score and the minimum possible score, divided by the difference between the theoretical maximum and minimum scores, multiplied by 100 . The formula used was the following: GIS $=[$ (Final score - minimal possible score)/(Theoretical maximal - minimal score)] x 100. The score ranges from 0 to $100(10)$.

The observational study was approved by the National Agency for Medicines and Medical Devices (NAMMD) and received positive opinion from the National Bioethics Committee for Medicine and Medical Devices (NBCMMD).

Statistical analysis. Statistical analysis was performed with SPSS version 15 (SPSS Inc., Chicago, IL, USA) and included the following: descriptive analysis, Mann-Whitney U tests, Chi-square test and ANOVA with Turkey's post hoc test.

The scales variables were reported with mean and standard deviation, and summarize categorical variables using frequencies and percentages. To investigate the relationship between CEAP classification, symptoms and impact on QoL, a logistic regression was performed. P-value $<0.05$ was considered to indicate a statistically significant difference.

\section{Results}

In total 1,893 patients were included in the observational study carried out in Romanian urban area. Most of the patients included were females $(79.08 \%)$ and $50.4 \%$ of patients belonging to age group (51-70 years). The average BMI was $27.9 \pm 5.03$ with no statistical sex difference.

Of the subjects $66.72 \%$ were enrolled in the study during visit to the family doctor's office for another disease, while only $18.86 \%$ of patients were enrolled during a visit for CVD consultation. Risk factors were present for most patients: prolong sitting ( $\geq 5 \mathrm{~h} /$ day) (42.02\% females, $46.7 \%$ males), prolonged standing ( $\geq 5 \mathrm{~h} /$ day) ( $44.4 \%$ females, $45.7 \%$ males). The CEAP classification placed most of the patients in $\mathrm{C} 3$ class (31.85\%), followed by C2 class $(28.00 \%), \mathrm{C} 1$ class $(21.02 \%)$ and C4a (8.87\%) (Table I).

Only $9.2 \%$ of patients enrolled in the study take regular physical activity, being a significant sex difference in favour of male population $(\mathrm{P}<0.05)$.

The most frequent CVD symptoms reported were heavy leg sensation $(85.74 \%)$, followed by swelling of the feet $(77.28 \%)$ and pain $(73.11 \%)$ and 'restless' feet $(72.42 \%)$, which occurred most often in the evening or after prolonged standing or sitting and during summer. Most of the patients reported 'low' or 'moderate' intensity of the CVD symptoms, $73.01 \%$ of the patients reported the presence of more than 3 concomitant CVD symptoms. The most frequent CVD signs were telangiectasia and reticular veins $(79.19 \%)$, varicose veins $(65.77 \%)$ and edema (53.35\%) (Table II).

Patients received the following treatment recommendation from GPs: lifestyle advice (99.21\% of patients) (most frequent advice given was to avoid long standing or sitting periods $(95.56 \%)$, to wear proper shoes $(80.51 \%)$ and to practice regular physical activities $(80.14 \%)$; systemic treatment $(96.21 \%$ of patients) with the most recommended systemic treatment being MPFF (48.39\%), followed by diosmin + micronized hesperidin $(21.52 \%)$; local treatment recommendation was received by $73.01 \%$ of the patients, while $30.74 \%$ of the patients were referred to a venous specialist.

Based on Mann-Whitney U tests, it was noted that CEAP C-classification of CVD was significantly higher for females compared to males $(\mathrm{P}<0.001)$. In addition, a significant positive correlation was observed between BMI and CVD C-class, but only for females $(\mathrm{P}<0.001)$ (Fig. 1).

A positive correlation was observed between the number of symptoms reported and the CEAP C-class $(\mathrm{P}<0.001)$ as 
Table I. Patient characteristics.

\begin{tabular}{|c|c|}
\hline Characteristics & $\%$ \\
\hline \multicolumn{2}{|l|}{ Age (years) } \\
\hline$<30$ & 2.80 \\
\hline $30-50$ & 29.11 \\
\hline $51-70$ & 50.40 \\
\hline$>70$ & 17.70 \\
\hline \multicolumn{2}{|l|}{ Sex } \\
\hline Female & 79.08 \\
\hline Male & 20.92 \\
\hline BMI $\left(\mathrm{kg} / \mathrm{m}^{2}\right)$ & $27.09 \pm 5.03$ \\
\hline \multicolumn{2}{|l|}{ Level of activity } \\
\hline Inactive & 34.07 \\
\hline Active & 32.91 \\
\hline Mixed & 33.02 \\
\hline Regular exercise taken & 9.20 \\
\hline \multicolumn{2}{|l|}{ Main reason for visiting the physician } \\
\hline Medical consult for other disease & 66.72 \\
\hline Medical consult for chronic venous disease & 18.86 \\
\hline Medical consult for hemorrhoidal disease & 2.32 \\
\hline Administrative matter & 12.10 \\
\hline \multicolumn{2}{|l|}{ Among women $(\mathrm{N}=1,497)$} \\
\hline \multicolumn{2}{|l|}{ No. of births } \\
\hline 0 & 11.49 \\
\hline 1 & 36.47 \\
\hline 2 & 38.68 \\
\hline$>2$ & 13.36 \\
\hline Current use of hormonal replacement therapy & 2.47 \\
\hline Current use of birth control pills & 5.95 \\
\hline
\end{tabular}

\begin{tabular}{llll} 
Risk factors & Female (\%) & Male (\%) & Total (\%) \\
\hline
\end{tabular}

Prolonged sitting

position (h/day)

$\begin{array}{llrr}<5 & 57.98 & 53.28 & 57.00 \\ 5-10 & 35.74 & 37.12 & 36.03 \\ >10 & 6.28 & 9.60 & 6.97\end{array}$

Prolonged standing position (h/day)

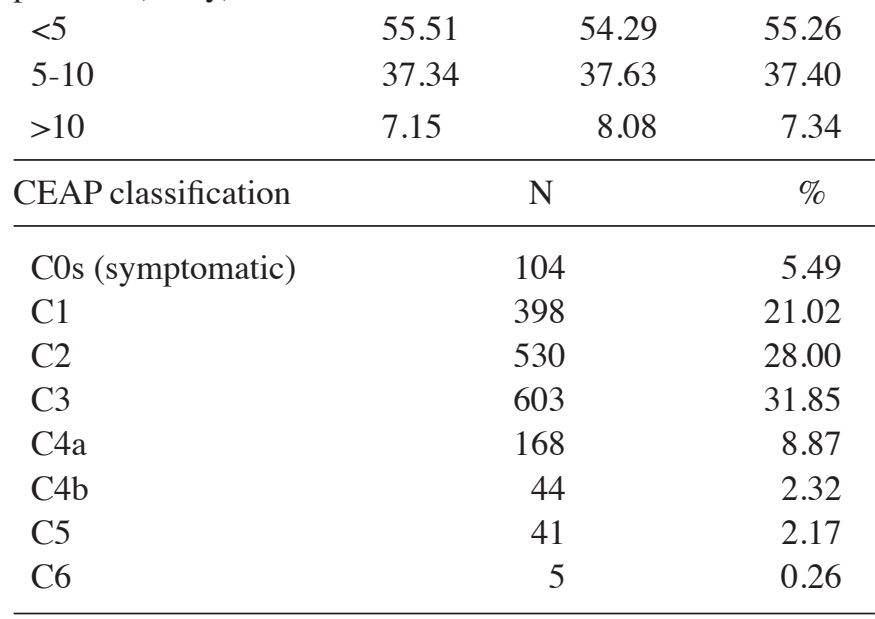

CEAP, clinical, aetiological, anatomical and pathophysiological.
Table II. CVD signs and symptoms.

\begin{tabular}{|c|c|c|c|}
\hline Most common CVD symptoms & $\mathrm{N}$ & $\%$ & VAS \\
\hline Feeling heavy legs & 1,604 & 85.74 & $5.3 \pm 1.83$ \\
\hline Sensation of swelling & 1,445 & 77.28 & $5.0 \pm 1.89$ \\
\hline Pain in the calf & 1,376 & 73.11 & $5.0 \pm 1.96$ \\
\hline Burning in the calf & 851 & 45.85 & $4.7 \pm 1.96$ \\
\hline Cramps in the calf & 1,134 & 60.38 & $4.8 \pm 1.97$ \\
\hline Tingling in the feet & 931 & 49.76 & $4.6 \pm 1.89$ \\
\hline 'Tired' or 'restless' feet & 1,359 & 72.42 & $5.1 \pm 1.90$ \\
\hline \multicolumn{4}{|l|}{$\begin{array}{l}\text { Time when CVD symptoms } \\
\text { appear at highest intensity }\end{array}$} \\
\hline At the end of the day & & 51.93 & \\
\hline $\begin{array}{l}\text { After long periods of orthostatic } \\
\text { position }\end{array}$ & & 82.14 & \\
\hline During the night & & 39.67 & \\
\hline $\begin{array}{l}\text { After a long period of } \\
\text { sitting on a chair }\end{array}$ & & 51.61 & \\
\hline During the summer & & 58.21 & \\
\hline After warm baths & & 26.47 & \\
\hline While walking & & 34.28 & \\
\hline Premenstrual & & 7.71 & \\
\hline Others & & 6.18 & \\
\hline \multicolumn{4}{|l|}{$\begin{array}{l}\text { CVD signs observed during } \\
\text { the clinical examination }\end{array}$} \\
\hline Telangiectasia, reticular veins & & 79.19 & \\
\hline Varicose veins & & 65.77 & \\
\hline Edema & & 53.35 & \\
\hline Skin changes (lipodermatosclerozis) & & 14.90 & \\
\hline Skin changes (white atrophy) & & 5.18 & \\
\hline Ulcer & & 2.59 & \\
\hline \multicolumn{4}{|l|}{$\begin{array}{l}\text { Number of CVD symptoms currently } \\
\text { present }\end{array}$} \\
\hline None & & 2.96 & \\
\hline 1 & & 3.75 & \\
\hline 2 & & 6.71 & \\
\hline 3 & & 13.58 & \\
\hline$>3$ & & 73.01 & \\
\hline
\end{tabular}

well as the intensity of symptoms measured on VAS and CVD CEAP C-class (Table III).

All patients completed the CIVIQ-20 questionnaire regarding quality of life and the results were translated into the GIS. The GIS median value for the entire group was $30.48 \pm 18.23$, with no significant sex difference. A significant positive correlation was found between GIS value and CVD C-class, for both sexes, as well as for the total group $(\mathrm{P}<0.001)$ (Table IV). A significant positive correlation was found between the number of symptoms and the GIS, for the total group of patients $(\mathrm{P}<0.001)$.

QoL was affected for most of the patients in 'a mild' or 'moderate' degree, being noticed as a significant negative impact on all physical, psychological, and social functioning and pain components of CIVIQ-20. The impact on each 
Table III. CVD symptoms intensity measured on VAS.

\begin{tabular}{|c|c|c|c|c|c|c|c|}
\hline \multirow[b]{2}{*}{ C-classification } & \multicolumn{7}{|c|}{ Symptom intensity measured on VAS (cm) } \\
\hline & $\begin{array}{l}\text { Feeling of } \\
\text { heavy legs }\end{array}$ & $\begin{array}{c}\text { Sensation of } \\
\text { swelling }\end{array}$ & $\begin{array}{l}\text { Pain in } \\
\text { the calf }\end{array}$ & $\begin{array}{l}\text { Burning } \\
\text { in the calf }\end{array}$ & $\begin{array}{l}\text { Cramps } \\
\text { in the calf }\end{array}$ & $\begin{array}{l}\text { Tingling } \\
\text { in the feet }\end{array}$ & $\begin{array}{l}\text { 'Tired' or } \\
\text { 'restless' feet }\end{array}$ \\
\hline $\mathrm{COs}$ & $4.56 \pm 1.52$ & $4.31 \pm 1.62$ & $4.46 \pm 1.41$ & $3.87 \pm 0.90$ & $3.97 \pm 1.44$ & $4.19 \pm 1.77$ & $4.49 \pm 1.54$ \\
\hline $\mathrm{C} 1$ & $4.44 \pm 1.79$ & $4.12 \pm 1.95$ & $4.06 \pm 2.03$ & $4.05 \pm 1.95$ & $4.09 \pm 1.98$ & $4.21 \pm 2.06$ & $4.39 \pm 1.84$ \\
\hline $\mathrm{C} 2$ & $5.12 \pm 1.90$ & $4.62 \pm 1.77$ & $4.85 \pm 1.96$ & $4.52 \pm 2.03$ & $4.59 \pm 1.96$ & $4.24 \pm 1.81$ & $4.89 \pm 1.80$ \\
\hline $\mathrm{C} 3$ & $5.53 \pm 1.67$ & $5.28 \pm 1.73$ & $5.29 \pm 1.77$ & $4.82 \pm 1.93$ & $4.99 \pm 1.91$ & $4.69 \pm 1.77$ & $5.37 \pm 1.86$ \\
\hline $\mathrm{C} 4 \mathrm{a}$ & $5.87 \pm 1.58$ & $5.76 \pm 1.80$ & $5.50 \pm 1.85$ & $5.03 \pm 1.69$ & $5.34 \pm 1.80$ & $4.81 \pm 1.70$ & $5.52 \pm 1.96$ \\
\hline $\mathrm{C} 4 \mathrm{~b}$ & $6.43 \pm 1.59$ & $6.24 \pm 1.75$ & $6.43 \pm 1.90$ & $5.54 \pm 1.86$ & $5.62 \pm 1.72$ & $5.67 \pm 1.99$ & $6.05 \pm 1.93$ \\
\hline $\mathrm{C} 5$ & $6.57 \pm 1.67$ & $6.74 \pm 1.80$ & $6.46 \pm 1.97$ & $5.63 \pm 2.17$ & $5.93 \pm 2.22$ & $5.55 \pm 2.18$ & $6.21 \pm 1.92$ \\
\hline C6 & $7.20 \pm 1.92$ & $7.20 \pm 1.48$ & $7.40 \pm 2.51$ & $6.50 \pm 2.65$ & $6.60 \pm 1.34$ & $6.80 \pm 2.39$ & $7.00 \pm 1.58$ \\
\hline P-value & $<0.001$ & $<0.001$ & $<0.001$ & $<0.001$ & $<0.001$ & $<0.001$ & $<0.001$ \\
\hline
\end{tabular}

VAS, Visual Analogue Scale.

Table IV. CIVIQ-20 global index score vs. C-class.

\begin{tabular}{|c|c|c|c|c|c|c|}
\hline C-classification & $\mathrm{N}$ & $\begin{array}{l}\text { CIVIQ-20 global } \\
\text { index score }\end{array}$ & $\mathrm{N}$ (female) & $\begin{array}{l}\text { CIVIQ-20 global } \\
\text { index score (female) }\end{array}$ & $\mathrm{N}$ (male) & $\begin{array}{l}\text { CIVIQ-20 global } \\
\text { index score (male) }\end{array}$ \\
\hline $\mathrm{COs}$ & 104 & $19.65 \pm 12.65$ & 85 & $20.43 \pm 12.07$ & 19 & $16.18 \pm 14.86$ \\
\hline $\mathrm{C} 1$ & 398 & $18.59 \pm 13.28$ & 335 & $18.60 \pm 12.93$ & 63 & $18.55 \pm 15.11$ \\
\hline $\mathrm{C} 2$ & 530 & $28.15 \pm 15.18$ & 414 & $29.09 \pm 14.93$ & 116 & $24.82 \pm 15.66$ \\
\hline $\mathrm{C} 3$ & 603 & $33.96 \pm 15.88$ & 490 & $34.28 \pm 15.44$ & 113 & $32.57 \pm 17.66$ \\
\hline $\mathrm{C} 4 \mathrm{a}$ & 168 & $43.70 \pm 18.27$ & 119 & $45.35 \pm 17.22$ & 49 & $39.69 \pm 20.23$ \\
\hline $\mathrm{C} 4 \mathrm{~b}$ & 44 & $58.41 \pm 13.95$ & 29 & $59.40 \pm 14.09$ & 15 & $56.50 \pm 13.97$ \\
\hline C5 & 41 & $62.44 \pm 15.45$ & 23 & $62.28 \pm 14.33$ & 18 & $62.64 \pm 17.21$ \\
\hline C6 & 5 & $76.25 \pm 8.24$ & 2 & $83.13 \pm 9.72$ & 3 & $71.67 \pm 3.15$ \\
\hline Total & 1893 & $30.48 \pm 18.23$ & 1497 & $30.41 \pm 17.63$ & 396 & $30.73 \pm 20.36$ \\
\hline P-value & & $<0.001$ & & $<0.001$ & & $<0.001$ \\
\hline
\end{tabular}

CIVIQ-20, Chronic Venous Insufficiency quality of life Questionnaire.

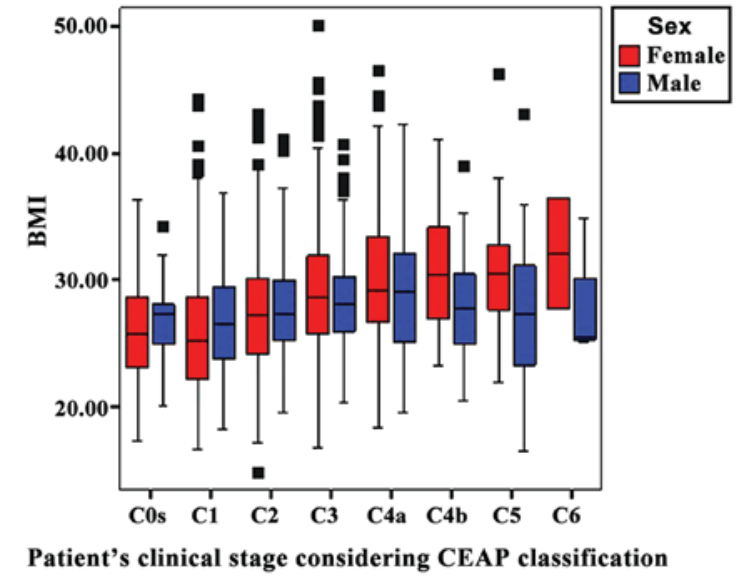

Figure 1. Correlation between BMI and C-class.

CIVIQ-20 items was positively correlated with severity of CVD CEAP class $(\mathrm{P}<0.001)$.

\section{Discussion}

CVD is a common problem among the adult population and has a significant impact on individuals and the entire health care system. Chronic vein abnormalities are present in up to $50 \%$ of individuals $(2,3,11,12)$. However, estimates of prevalence rates of chronic venous disease vary depending upon the population studied (13). In Romania, Vein Direction study showed that, in June-July 2015, the ratio of newly diagnosed CVD cases was 369.5 for every 1,000 patients and the recorded CVD prevalence during this period was $68.40 \%$ (14).

Nevertheless, without a proper CVD management, patients might reach the stage where they will no longer be able to perform daily activities and higher CEAP classification indicates a higher socioeconomic problem. In case CVD pathology is associated with other pathologies, mainly diabetes mellitus, the CVD ulcers could become extremely difficult to treat (15). In addition to CVD impact, for those patients, the diabetic neuropathy is associated with a whole range of local and 
general complications that inflict important health care costs and reduce the patient's quality of life (16).

One recent study demonstrated that female subjects with cardiometabolic risk factors or female diabetic patients are at greater risk of developing early chronic venous disorder than the male subjects (17), nevertheless the factors that determine whether a given patient will progress from mild to more severe form of CVD remain largely unknown.

An important aspect regarding the present observational study is that according to the inclusion criteria all patients were previous or during the current GP visit diagnosed with CVD. Despite this, only $18.86 \%$ of patients visited the GPs for 'medical consultation for CVD', confirming the low addressability rate, which was detected also in previous observational studies. The GPs referred $30.7 \%$ of the patients to a vein specialist, most of the referred patients being classified with a higher $\mathrm{C}$-class, fact that is suggestive for trying a conservative treatment in early stage of CVD and most of the patients received lifestyle advice, as well as venoactive pharmacological treatment. Another important aspects that need to be considered are the CVD prevention measurements, as well as the patient's adherence to the medical treatment. Use of textile biomaterials in patients with high risks in developing CVD, might be an efficient method of preventing the disease (18). On the other hand, for increasing patient treatment adherence the pharmacist plays an important role, by delivering correct and complete information that will enable patients to take correct decisions (19).

Patients who addressed GPs for 'other medical consultation' presented CVD signs consistent with an advance stage of CVD, suggesting that patients are ignoring the CVD signs and are visiting physicians in a late phase of CVD, despite of the fact that their quality of life was profoundly affected.

The study proved that CVD diagnosis was established with a relative delay, most of the patients being initially diagnosed as CEAP-class C3. This might suggest that additional to encouraging patients to address physicians earlier, specialized training is needed for GPs in order to detect CVD signs at earlier stage and implement therapeutic management as early as possible. A similar conclusion regarding adequate screening and additional training for physicians was reached by the Vein Consult Program (1).

For this observational study the CVD was classified by using only the $\mathrm{C}$ (clinical) part of CEAP and classification was done by GPs, who are not routinely using the CEAP classification. This fact could link to a moderate reproducibility of data, as already described in the literature (20).

Obesity, due to increased abdominal pressure that leads to a greater reflux, increased venous pressure and vein diameter, represents a high impact CVD risk factor, together with the lack of regular physical exercise (21). In the present study a positive significant correlation was observed between BMI, and the severity of CVD for the female group, but not for the male group.

During the study it was noted that female population had a significantly higher C-class compared with men, fact similar with other data in the literature (22).

In the present study $97.04 \%$ of all enrolled patients reported at least one CVD symptom, and $73.01 \%$ of patients reported more than 3 concomitant symptoms. The most common symptoms were heavy legs $(85.74 \%)$, sensation of swelling feet
(77.28\%) and pain in the calf $(73.11 \%)$, followed by cramps in the calf $(60.38 \%)$. A positive correlation was observed between the number of symptoms reported and the CEAP C-class as well as the intensity of symptoms measured on VAS $(\mathrm{cm})$ and CVD CEAP C-class.

A positive significant correlation was found between the severity of CVD C-class and degree in which quality of life is affected (GIS). QoL was affected even in the very early stage of CVD (namely COs) and with the first symptom reported.

Quality of life was affected to a certain degree for almost all patients, even for those included by physicians in CEAP COs class, were patients reported moderate or even considerable pain.

It is known that chronic leg ulcers due to their recurrent nature, difficult-to-treat and the long-term therapy required for healing are high resources consumer for the healthcare systems, as well as they impact on patient's quality of life in a prohibitive manner (23). When patients with chronic ulcer were analysed, a very severe impact on quality of life level was noted correlating with depression symptoms which were commonly present. Similarly, a systematic review conducted by Herber et al concluded that patients with leg ulcers have significantly higher levels of pain, limitations regarding functional and social activities correlated with lower vitality and emotional limitations (24).

All CIVIQ-20 items (physical, psychological, social and pain) were affected for most of the patients, and the degree in which they were affected was positively correlated with CVD severity CEAP class, is suggestive of the magnitude of CDV impact on patients' life.

\section{Acknowledgements}

OV received honoraria for the interpretation of data.

\section{Funding}

The observational study was funded by Servier Pharma (Bucharest, Romania).

\section{Availability of data and materials}

The datasets generated and/or analysed during the present study are not publicly available due to the fact that they belong to Servier, as Sponsor of the study, but are available from the corresponding author on reasonable request, and with prior permission of Servier.

\section{Authors' contributions}

DEB, TF, SB, IAM contributed to the acquisition of the data and critical revision of manuscript for important intellectual content. OV was responsible for the analysis of the patient data and contributed to writing the manuscript. All authors read and approved the final version of the manuscript.

\section{Ethics approval and consent to participate}

The present study was approved by the National Bioethics Committee of Medicines and Medical Devices (NBCMMD; 
approval no. 15 SNI; Bucharest, Romania), and written informed consent was obtained from each participant.

\section{Patient consent for publication}

Not applicable.

\section{Competing interests}

IAM is an employee of Servier Pharma Romania. The other authors declare that they have no competing interests.

\section{References}

1. Rabe E, Guex JJ, Puskas A, Scuderi A, Fernandez Quesada F and Coordinators VC; VCP Coordinators: Epidemiology of chronic venous disorders in geographically diverse populations: Results from the Vein Consult Program. Int Angiol 31: 105-115, 2012.

2. Callam MJ: Epidemiology of varicose veins. Br J Surg 81: 167-173, 1994

3. Evans CJ, Fowkes FG, Ruckley CV and Lee AJ: Prevalence of varicose veins and chronic venous insufficiency in men and women in the general population: Edinburgh Vein Study. J Epidemiol Community Health 53: 149-153, 1999.

4. Beebe-Dimmer JL, Pfeifer JR, Engle JS and Schottenfeld D: The epidemiology of chronic venous insufficiency and varicose veins. Ann Epidemiol 15: 175-184, 2005.

5. Kaplan RM, Criqui MH, Denenberg JO, Bergan J and Fronek A: Quality of life in patients with chronic venous disease: San Diego population study. J Vasc Surg 37: 1047-1053, 2003.

6. Jawien A: The influence of environmental factors in chronic venous insufficiency. Angiology 54 (Suppl 1): S19-S31, 2003.

7. Lacroix P, Aboyans V, Preux PM, Houlès MB and Laskar M: Epidemiology of venous insufficiency in an occupational population. Int Angiol 22: 172-176, 2003.

8. van Korlaar I, Vossen C, Rosendaal F, Cameron L, Bovill E and Kaptein A: Quality of life in venous disease. Thromb Haemost 90: 27-35, 2003.

9. Launois R, Mansilha A and Jantet G: International psychometric validation of the Chronic Venous Disease quality of life Questionnaire (CIVIQ-20). Eur J Vasc Endovasc Surg 40: 783-789, 2010.

10. CIVIQ Users' Guide: Calculation of the global index score. https:// www.civiq-20.com/scoring-missing-data/calculation-global-indexscore. Accessed August 27, 2017.

11. Zahariev T, Anastassov V, Girov K, Goranova E, Grozdinski L, Kniajev V and Stankev M: Prevalence of primary chronic venous disease: The Bulgarian experience. Int Angiol 28: 303-310, 2009.
12. Brand FN, Dannenberg AL, Abbott RD and Kannel WB: The epidemiology of varicose veins: The Framingham Study. Am J Prev Med 4: 96-101, 1988.

13. Criqui MH, Jamosmos M, Fronek A, Denenberg JO, Langer RD, Bergan J and Golomb BA: Chronic venous disease in an ethnically diverse population: The San Diego Population Study. Am J Epidemiol 158: 448-456, 2003.

14. Feodor T, Vittos O and Mitea L: Chronic venous disease in Romania: An epidemiological study. Int Angiol 35: (Suppl 1): 63 , 2016.

15. Nwabudike LC and Tatu AL: Magistral prescription with silver nitrate and Peru Balsam in difficult to heal diabetic foot ulcers. Am J Ther Jun 13, 2017 (Epub ahead of print). doi: 10.1097/ MJT.0000000000000622.

16. Căruntu C, Negrei C, Boda D, Constantin C, Căruntu A and Neagu M: Biotechnological advances for diagnosis of peripheral diabetic neuropathy. Rom Biotechnol Lett 19: 9846-9858, 2014.

17. Zhong J, Chen J, Zhao ZG, He HB, Yan ZC, Liu DY, Zhu ZM and Ni YX: Diabetes mellitus is associated with early chronic venous disorder of the lower extremities in Chinese patients with cardiometabolic risk factors. Diabetes Metab Res Rev 30: 505-512, 2014.

18. Brănisteanu DE, Nichifor M, Dorobăt CM, Brănisteanu DC, Petrariu FD, Molodoi AD, Radu DC and Boda D: Use of textile biomaterials for the topic treatment of chronic venous disease. Rom Biotechnol Lett 20: 10618-10625, 2015.

19. Ratiu MP, Purcarea I, Popa F, Purcarea VL, Purcarea TV, Lupuleasa D and Boda D: Escaping the economic turn down through performing employees, creative leaders and growth driver capabilities in the Romanian pharmaceutical industry. Farmacia 59: 119-130, 2011.

20. Sinabulya H, Holmberg A and Blomgren L: Interobserver variability in the assessment of the clinical severity of superficial venous insufficiency. Phlebology 30: 61-65, 2015.

21. van Rij AM, De Alwis CS, Jiang P, Christie RA, Hill GB, Dutton SJ and Thomson IA: Obesity and impaired venous function. Eur J Vasc Endovasc Surg 35: 739-744, 2008.

22. Vuylsteke ME, Thomis S, Guillaume G, Modliszewski ML, Weides $\mathrm{N}$ and Staelens I: Epidemiological study on chronic venous disease in Belgium and Luxembourg: Prevalence, risk factors, and symptomatology. Eur J Vasc Endovasc Surg 49: 432-439, 2015.

23. Scott TE, LaMorte WW, Gorin DR and Menzoian JO: Risk factors for chronic venous insufficiency: A dual case-control study. J Vasc Surg 22: 622-628, 1995.

24. Herber OR, Schnepp W and Rieger MA: A systematic review on the impact of leg ulceration on patients' quality of life. Health Qual Life Outcomes 5: 44, 2007. 